\title{
Multi-objective Optimization of Kerf-taper and Surface-roughness Quality Characteristics for Cutting-operation On Coir and Carbon Fibre Reinforced Epoxy Hybrid Polymeric Composites During $\mathrm{CO}_{2}$-Pulsed Laser-cutting Using RSM
}

\author{
Yadvinder Singh, et al. [full author details at the end of the article]
}

Accepted: 29 March 2021 / Published online: 24 May 2021

(c) Crown 2021

\begin{abstract}
Current research focuses on optimizing various quality characteristics for kerf geometry generated through laser cutting of Coir fibre/carbon fibre/epoxy resin hybrid composite adjacent to straight cut profile employing pulsed $\mathrm{CO}_{2}$ laser system. The Kerf taper (KT) and the Surface roughness (SR) are the main quality parameters discussed. Dependent on significant process parameters, namely gas pressure, cutting speed, pulse frequency and pulse width predictive models were developed. In accordance with Taguchi's $\mathrm{L}_{9}$ orthogonal array (OA), the cutting trials are designed. Process-parametric optimization was performed using Response Surface Methodology (RSM). Furthermore, experiments were performed to obtain experimental data for the analysis of cut quality features. The impact of the input variables on the response characteristics is also explored. The morphological characterizations have been performed to analysis the effect of machining-variables and cut-quality for the top and bottom kerf widths with various laser cutting variables in the pulse laser-cutting of Coir-fibre/carbon-fibre/epoxy-resin hybrid composite. For SR and KT, the developed second order surface response model was found very successful. The optimal levels of cutting variables for KT are established at Gas pressure- $6 \mathrm{~N} / \mathrm{mm}^{2}$, pulse width-2.04 ms, cutting speed- $8.01 \mathrm{~mm} / \mathrm{s}$, pulse frequency-15 Hz, for sample A1, Gas pressure-5.47 N/mm ${ }^{2}$, pulse width- $2.5 \mathrm{~ms}$, cutting speed-8.81 mm/s, pulse frequency-8.43 Hz, for sample A2, Gas pressure-3.85 N/mm², pulse width-1.5 ms, cutting speed- $9.06 \mathrm{~mm} / \mathrm{s}$, pulse frequency- $5 \mathrm{~Hz}$, for sample A3 additionally for SR Gas pressure- $2 \mathrm{~N} / \mathrm{mm}^{2}$, pulse width- $1.5 \mathrm{~ms}$, cutting speed-7 mm/s, pulse frequency-5 Hz, for sample A1, Gaspressure-2.36 N/mm ${ }^{2}$, pulse width- $1.5 \mathrm{~ms}$, cutting speed-7 mm/s, pulse frequency-15 Hz, for sample A2, Gaspressure- $6 \mathrm{~N} / \mathrm{mm}^{2}$, pulse width-1.5 ms, cutting speed-11 mm/s, pulse frequency-8.73 Hz, for sample A3. Regression results and linear and square impact of laser cutting variables have been revealed to be important to validate the model.
\end{abstract}

Keywords Coir fibre $\cdot$ Carbon fibre $\cdot$ Kerf taper $\cdot$ Surface roughness $\cdot$ RSM · Morphological 


\section{Nomenclature}

$\begin{array}{ll}\text { Ra } & \text { Arithmetical Mean Surface Roughness }(\mu \mathrm{m}) \\ \text { OA } & \text { Orthogonal Array } \\ \text { KT } & \text { Kerf Taper } \\ \text { SR } & \text { Surface Roughness } \\ \text { RSM } & \text { Response Surface Methodology } \\ \text { VAHL } & \text { Vacuum Assisted Hand Lay-up } \\ \text { BKW } & \text { Bottom Kerf Width } \\ \text { GRA } & \text { Grey Relational Analysis } \\ \text { TKW } & \text { Top Kerf Width } \\ \text { ANOVA } & \text { Analysis of Variance } \\ \text { ANN } & \text { Artificial Neural Network }\end{array}$

\section{Introduction}

Natural fibre-reinforced composites are in huge demand as fibres are natural and readily available, as well as being less costly, reusable, biodegradable and ecofriendly compared to other available materials. However, it's claimed that more the carbon fibre exists in the composite, the greater would be the developed strength. In the different modes of failure, hybrid composite containing carbon fibres and natural fibres have undergone improved durability and a major improvement. This would result in higher energy absorption and considerably more effective tolerance to damage. The likelihood that carbon fibre composites have a conventional market for span of life and particularly sophisticated applications, namely safety, sports cars, \& aeronautical industries is also necessary to take into account [1].

Coir fibre / Carbon fibre/ Epoxy resin hybrid composite cutting using Laser Beam Machining (LBM) is of great interest because it is a non-contact method; as a matter of fact, traditional machining poses tool wear more rapidly because of the abrasive behaviour of the fibres of carbon, coolant fluid can cause significant damage to absorption as well as mechanical stresses which further can result in cracking throughout the matrix.

On the same note, utilization of carbon fibre reinforced composites in various engineering sectors for instance automotive sector, aeronautical structures, sports goods manufacturing, machine components and so on has remarkably increased in recent years due to the numerous significant advantages like resistance to corrosion over high temperatures, stable dimensional components and many more. Moreover, for their structural applications, machining of these composites is needed. Different frictional forces are produced in their conventional machining and decrease their cut efficiency. The laser cutting quality relies mainly on the appropriate choice of the factors like the material characteristics, cutting variables and laser parameters. With low cost and better machinability, it possesses high accuracy and flexibility in the absence of moisture effect and gives enhanced cut quality and operation precision. Moreover, LBC can provide complex shapes with precise cut edge geometries with a higher removal rate of material for a wide variety of materials, for instance ceramics, composites, metals, and non-metals. 
[2-5]. A laser cut geometry is defined in terms of the factors of the quality of kerf, like KT, KW, \& SR. Such parameters specify the geometrical consistency, and accuracy of the cut. [4-11].

The impact of gas pressure, pulse duration, pulse energy, pulse repetition rate \& cutting speed on the widths of top \& bottom kerf, KT and heat affected zone (HAZ) were investigated by Mathew et al. [5] during Nd: YAG laser cutting of composites of carbon fibre reinforced plastic (CFRP). It is also found that the most dominating variables for the widths of kerf were pulse energy and pulse repetition rate. The investigators also found that no cut-situation was observed at higher cutting rates [5-10].

Laser cutting of nano-Hydroxyapatite (HA) treated with microwave reinforced ultra-high molecular wt. polyethylene (UHMPE) using laser beam machining process was analysed by Nishant et al. to boost mechanical strength. In UHMPE, the mass proportions of nano-HA were 20 percent, 15 percent, and 10 percent. Through 20 percent nano-HA addition, 3.64 percent raise is observed in surface roughness. Also, HAZ and defect factor decreased by 64.32 percent and 35.75 percent respectively [8]. In the research made by Elsheikh et al. [9]., optimisation of laser cutting variables includes assisted gas pressure, cutting speed, laser beam strength, and thickness of sheet to increase the kerf consistency, during laser processing of Poly (methyl metha-crylate) (PMMA) sheets using $\mathrm{CO}_{2}$ pulsed laser system. The results obtained showed that with even small improvement in cutting variables will leads to increase the top as well as bottom kerf widths, whereas raising the laser power or cutting speed will result in an increase in the taper of the kerf. The genetic algorithm (GA) was used as a function objective for minimising the taper of kerf to choose the optimum cutting variables by the means of established regression model. The implementation of the suggested solution is sufficient of reducing the taper of $1.92^{\circ}$ to $0.02^{\circ}$ although preserving the optimal width of the kerf at a fair value $(\geq 0.5 \mathrm{~mm})$. Laser cutting of numerous materials, namely Inconel 625, steel 304, Ti6Al-4 V alloy, and alumina, was evaluated by Yilbas et al. to determine the changes in kerf width across the cut surface. Highly pressurised nitrogen as assisting gas is utilized in the trail runs to stop oxidation in the cutting area. It was observed that the lump parameter analysis, predicted size of the kerf width align well with the testing results. With increasing output power, size variance of the kerf width increases. However, with growing laser cutting speed, this behaviour reverses. [11].

For the cutting of CFRP composites, Leone et al. [12] utilised a Nd: YAG $150 \mathrm{~W}$ laser pulsed type. They found that the precise selection of parameters for laser cutting can minimise the HAZ and KT. Through, the laser cutting of aramid fibre reinforced polymer (AFRP) and glass fibre reinforced polymer (GFRP) composite specimen of varying thickness, Cenna et al. [13] established an energy balance equations-based model to forecast width of kerf and KT. They have shown that with proliferating cutting speed for both materials, the kerf angle is reducing.

During Nd: YAG laser cutting of AFRP, Gautam et al. [14] estimated the impact of various variables of laser cutting namely pulse frequency, compressed air pressure, pulse duration, lamp current, and cutting speed, on top and bottom kerf deviation. For the top \& bottom kerf deviation preceded by pulse frequency, they find that the highest dominating factor is lamp current. Limited research work on the laser 
cutting of Basalt fibre reinforced composites (BFRC) as an entity or component of hybrid laminates is found in the comprehensive literature survey.

To optimise kerf deviation, KT and kerf width, Gautam and Mishra [15] carried out the cutting through laser of $1.60 \mathrm{~mm}$ thick BFRC sheets; they also used a fireflybased approach for multi-objective optimization. They observed that the width of kerf and KT were indispensably affected by lamp current. They often noticed that all characteristics of quality of kerf have a marginal effect on the frequency of pulses.

A Nd: YAG pulsed laser in wave mode was used by Thawari et al. [16] to examine the impact of spot overlap while cutting of Ni-based superalloy sheet with thickness of $1 \mathrm{~mm}$. It was revealed that while SR declines with the growth of spot overlap, width of kerf rises at the top \& bottom edge. They also found that a higher kerf taper is responsible for the widest pulse period $(2 \mathrm{~ms})$ reviewed in the analysis. Rao et al. [17] analysed the outcomes of frequency, gas assist strain, cutting speed and pulse length while cutting of straight and curved laser cuts of thin Ni-based superalloy sheets. Simultaneously, with entropy measurement method using grey relational analysis (GRA), KT, kerf width, and kerf deviation were optimised. The implications of cutting speed, pulse frequency, oxygen pressure, and pulse width were studied by Sharma et al. [18] through Ni-based laser cutting of thin sheets of super alloy along both curved and straight cut profiles. At the same time, they optimised kerf distance, KT, and kerf deviation employing the Taguchi Method where $\mathrm{L}_{27} \mathrm{OA}$ was considered to analyse both curved and straight cut profiles. In comparison with straight cut, they noticed that the angle of KT is more than a straight cut for curved cutting.

Adalarasan et al. [19-22] studies on the performance of the $\mathrm{CO}_{2}$ pulsed laser cutting method on composite of $\mathrm{Al} 6061 / / \mathrm{Al}_{2} \mathrm{O}_{3} / \mathrm{SiCp}$ of non-contact form. For the distinct combinations of cutting variables namely pulsing frequency, laser power, gas pressure assist \& cutting speed, quality characteristics were studied. The cutting studies were planned as per to Taguchi's $\mathrm{L}_{18} \mathrm{OA}$ as well as a hybrid approach was disclosed for the prediction of the optimal combination of laser cutting variables using the grey-based response surface methodology (GRSM). In the responses obtained with the optimum setting of variables, a major improvement was noted in the surface finish. The predicted grey relation grade values and the values observed experimentally matched fairly well, suggesting a better fitness model. In order to illustrate the increased surface finish carried out by optimal variable configuration, the P-profile plots were demonstrated. An improved texture of the cut surface acquired from GRSM setting is seen in the atomic force microscopy images.

Choudhary et al. [23-25] employed $\mathrm{CO}_{2}$ laser cutting of polycarbonate (PC) polypropylene (PP), and polymethyl methacrylate (PMMA) to analyse the impact of the primary laser cutting input variables (compressed air pressure, cutting speed, \& laser power) on the laser cut quality of the various polymers and to develop model equations relating to the output input parameters. Surface roughness and dimensional accuracy were the output quality characteristics examined. Response surface methodology has developed predictive models (RSM). It was discovered that a linear function of the input variables modelled the response well. PMMA has greater cut edge surface quality than PP and PC for surface roughness. The response models created can be employed by the manufacturing sector for practical purposes. 
In CNC face milling operations, to enhance the cutting parameter, Abbas et al. [26] presented an algorithm employing an ANN with the Edgeworth-Pareto technique. To boost surface roughness and minimum unit-volume material removal rates (Tm), the collection of parameters is changed to minimize production costs and improve accuracy. In Matlab, an ANN algorithm is built based on a 3-10-1 MultiLayer Perceptron, which predicts \pm 5.78 percent accuracy of the Ra of the workpiece surface within the range of the feed rate, speed, and cutting depth of the experimental angular spindle. For the finished grade-H steel workpiece, an unparalleled Pareto border for Ra and Tm was obtained employing an ANN algorithm that was then used to evaluate optimized cutting conditions. Depending on the production target, one of two sets of optimal machining conditions can be used: the first sets the minimum cutting capacity, while the other sets the maximum Tm with a slight increase in milling cost (under 5\%).

The statistical ANOVA was used by Khan et al. [27] to determine the key factors influencing the mentioned responses. The multi-objective optimization of surface temperature, surface quality and normal force for system-wide optimal performance was performed by the Grey-Taguchi method. The central composite experimental design plan was used to orient the inputs in relation to the machinability indices of surface grinding of AISI D2 steel under dry, flood cooling, and minimum quantity lubrication (MQL) conditions. The use of MQL flow rate as an input adds additional novelty to this study. RSM was used to formulate the mathematical models. The developed models have been found to be statistically important, with an optimum cutting depth of $15 \mu \mathrm{m}$, a table speed of $3 \mathrm{~m} / \mathrm{min}$, a cutting speed of $25 \mathrm{~m} / \mathrm{min}$ and a MQL flow rate of $250 \mathrm{~mL} / \mathrm{h}$. Also, it was observed that due to its efficient penetration capacity and improved heat dissipation characteristics, MQL exceeded surface grinding in the dry as well as wet condition.

The optimum conditions for fly (face) milling of parts made from AISI 1045 steel were determined by Pimenov et al. [28] The key parameters in this study are the surface quality produced, the cost of the components of the cutting tool, the energy consumption, the wear of the cutting tool, and the rate of material removal. On the obtained experimental results and causing non-linear mathematical equations with a large coefficient of determination $\left(\mathrm{R}^{2}=0.98\right)$, a multilayer regression analysis was performed. Consideration was provided to the impact of cutting speed $(\mathrm{Vc})$, feeding per tooth $(f z)$, flank wear $\left(\mathrm{V}_{\mathrm{B}}\right)$ on surface roughness $(\mathrm{Rz})$, material removal rate (MRR), cutting power $(\mathrm{Pc})$, sliding distance $(l \mathrm{~s}), \&$ tool life $\left(\mathrm{T}^{l}\right)$. The overall results, calculated by GRA, revealed that for cutting velocity $v c=392.6 \mathrm{~m} / \mathrm{min}$, feed per tooth $f \mathrm{z}=0.25 \mathrm{~mm} /$ tooth, and machined length $1=5 \mathrm{~mm}$, the optimum fly milling efficiency for rapid development (case 1). Although cutting velocity $v c=392.6 \mathrm{~m} /$ $\min$, feed per tooth $f \mathrm{z}=0.125 \mathrm{~mm} /$ tooth, and machined length $l=5 \mathrm{~mm}$ are the optimal parameters for resource (tools) conservation (case 2).

Mishra et al. [29] while cutting Basalt, Glass, and Kevlar-29 fibres hybrid composite employing Nd: YAG laser to optimize TKW \& BKW with the help of GRA to optimize the parameter. They reported a substantial increase in the top \& bottom kerf deviations of 18.64 percent and 10.34 percent respectively.

Yusuff et al. [30] created a hybrid composite using a vacuum infusion technique to combine two distinct reinforcements: fine kenaf fibre and carbon fibre with an 
epoxy matrix. At 40 and 50 percent vol., the fiber content varied. The carbon fiber reinforced epoxy matrix sample and the epoxy matrix reinforced by kenaf fiber were also manufactured as a comparison. The effect of various fibers/matrix ratios of the hybrid composite was investigated using ASTM D3039 and ASTM D790 tensile and flexural measures. Using the scanning electron microscope and the optical microscope, the fractures and mode failures of hybrid composites have been characterized. The result shows that hybrid composite exhibits strong tensile and flexural strength with a fiber/matrix ratio of $40 / 60 \mathrm{vol}$. percent in which both values gained at $325.70 \mathrm{MPa}$ and $345.23 \mathrm{MPa}$, respectively.

The literature review reveals that the utility of LBC for coir and carbon hybrid composite fibre were very rare explored. Therefore, we have provided here a complete research in order to reduce the scientific gap on the laser cutting machining of Coir fibre/ carbon fibre/ epoxy resin reinforced hybrid composite. Further, this research study aimed to figure out the optimal variables for cutting Coir fibre / Carbon fibre / Epoxy resin hybrid composite with the aid of the pulsed $\mathrm{CO}_{2}$ laser. Combination of Carbon fiber (woven type) and coir fiber was explored for the first time. Similarly, Vacuum assisted hand lay-up/ vacuum bagging method is employed for the first time to fabricate coir/carbon fibre together to form a hybrid composite. Different input variables have been studied (i.e., pulse width, cutting speed pulse frequency, and gas pressure) and their response variables have been optimised (i.e., kerf taper as well as surface roughness characteristic) by employing RSM with multi-optimizer. Coir fibre/Carbon fibre/Epoxy resin hybrid composite specimens was fabricated of thicknesses $3 \mathrm{~mm}, 3.5 \mathrm{~mm}$ and $4.5 \mathrm{~mm}$ with three types of fiber-weight percentages of 30\%, 20\% and 10\% of coir fibre. The levels of the process variables and their combinations were determined via Taguchi $\mathrm{L}_{9} \mathrm{OA}$. Response surface methodology was employed to run the experimental trials along the straight cut-profile. Additionally, RSM multi-optimizer outcomes were found by using the MINITAB software. The highly-magnified, SEM micro-images were obtained at different laser cutting variables after the laser-cutting of Coir fibre/carbon fibre/epoxy resin reinforced hybrid composite which illustrates the laser-cut quality, Delamination, Thermal-degradation and Peeling-off structure of coir as well as carbon fibers at the top side during laser cut and narrow heat-affected-zone (HAZ) at the top surface.

\section{Experimentation}

\section{Materials}

The coir fibres were obtained from local sources and 10 percent of the $\mathrm{NaOH}$ solution was utilized to chemically treat coir fibers to enhance their compatibility with epoxy and carbon fibre. The 400 GSM woven carbon fibre was also used as a reinforcement material. For composite manufacturing, the epoxy resin (YD535LV) and hardener (TH7255) were supplied by CF composites, New Delhi. The resin and the hardener were incorporated in a ratio of 10:1. 


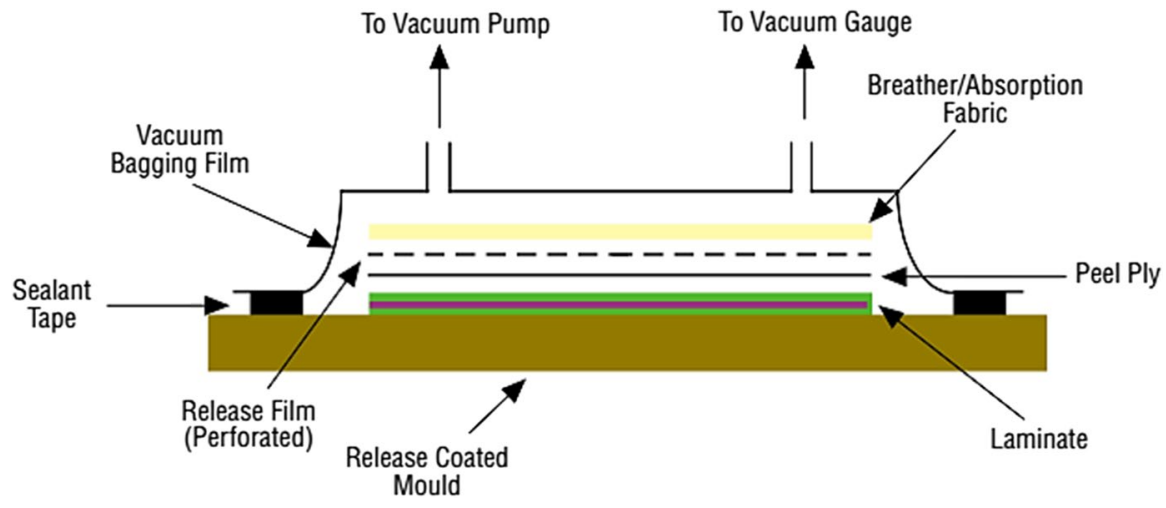

Fig. 1 Schematic of hand lay-up/ method (vacuum assisted) [31, 32]

\section{Methods}

The hybrid composite was manufactured through vacuum assisted hand lay-up (VAHL) technique illustrated in Figs. 1 and 2. Various sheets of hybrid composite were made by varying the coir fibre percentage at three levels 30\%, 20\% and $10 \%$ of coir fibre having thicknesses $4.5 \mathrm{~mm}, 3.5 \mathrm{~mm}$, and $3 \mathrm{~mm}$ (designated as A1, A2, A3).

As illustrated in Fig. 2a, b, the fabricated samples of Coir fibre /carbon fibre/ Epoxy resin hybrid composite processed through VAHL technique, and hybrid composite work piece after laser cutting was performed.

The dimensions of fabricated sheets are shown in Table 1. Mechanical, thermal, and morphological characteristics of the fabricated hybrid composite has been addressed $\&$ published in our previous article [32] and are briefly discussed mechanical properties in tabulated form in Table 2.
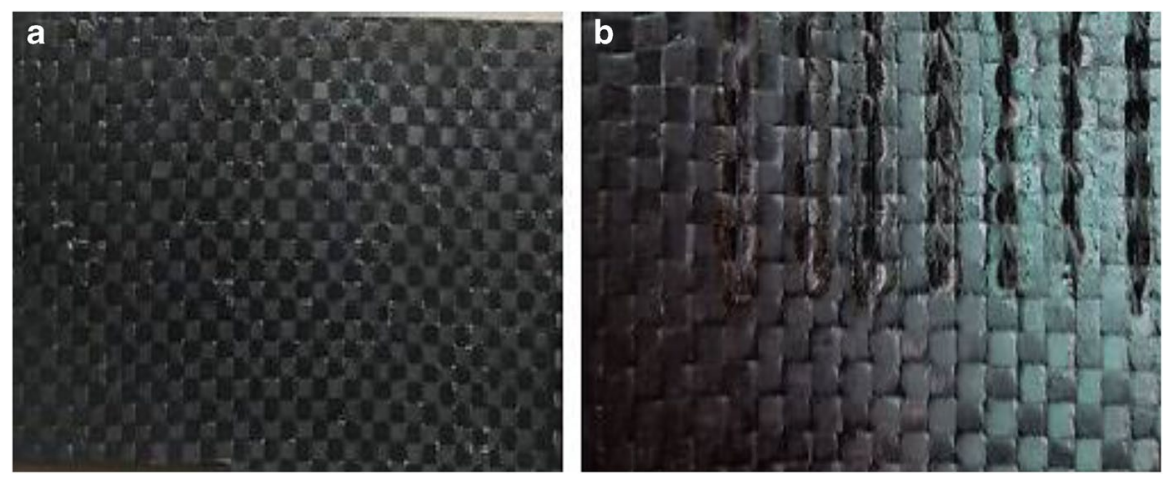

Fig. 2 (a) Fabricated Coir fibre /carbon fibre/Epoxy resin hybrid composite through VAHL technique (b) Machined hybrid composite using Laser cutting [32] 
Table 1 Dimensions of fabricated composite sheets [32]

\begin{tabular}{ll}
\hline Specimen Type & Dimensions $(\mathrm{mm})$ \\
\hline A1 & $25 \times 25 \times 4.5$ \\
A2 & $25 \times 25 \times 3.5$ \\
A3 & $25 \times 25 \times 3$ \\
\hline
\end{tabular}

SEM micrograph of fractography samples of coir fiber/carbon fiber/epoxy hybrid composite after physical testing without alkali treatment indicates weak bonding of the fiber-matrix interface and further pull-out of the fiber as illustrated in Fig. 3a Also, in Fig. $3 b$ the morphological study of the manufactured hybrid composite (10wt percent of $\mathrm{NaOH}$ solution) was performed with chemical treatment, which indicates that the coir fiber has been uniformly distributed. The inclusion of carbon fiber within the matrix provides strong reinforcement bonding as well as interfacial adhesion to the matrix.

\section{Experimentation Setup}

For the present article, investigative trials were performed on a $\mathrm{CO}_{2}$ pulsed Laser set-up for cutting, available at Sahaj Anand Laser Technology Limited, Gandhinagar. Fabricated Coir fibre/carbon fibre/ epoxy resin reinforced hybrid composite sheets of thickness $4.5 \mathrm{~mm}, 3.5 \mathrm{~mm}$, and $3 \mathrm{~mm}$ were employed for the study. Distance stand-off $(2 \mathrm{~mm})$, diameter of nozzle $(1.5 \mathrm{~mm})$, and focal length $(125 \mathrm{~mm})$, through all the experimentation, they were kept constant. As the system is fitted with a Siemens controller, all parameters are precisely controlled (see Fig. 4a, b).

The system was able to use oxygen as well as nitrogen an assisted gas at the right angle and co-axially to the laser beam. The utilization of nitrogen as an inert gas was determined through trail. The cutting parameter's range is determined based on the pilot testing along straight profile by cutting Coir fibre / carbon fibre/ epoxy resin hybrid composite sheets.

\section{Design of Experiments}

A well-established investigative trials plan will significantly turn down the total number of tests without compromising the quality of any manufacturing method during experimental testing. Taguchi's robust methodology of designing parameter

Table 2 Mechanical property of the fabricated hybrid composite [32]

\begin{tabular}{lllll}
\hline Specimen type & $\begin{array}{l}\text { Tensile strength (N/ } \\
\left.\mathrm{mm}^{2}\right)\end{array}$ & $\begin{array}{l}\text { Compressive strength } \\
\left(\mathrm{N} / \mathrm{mm}^{2}\right)\end{array}$ & $\begin{array}{l}\text { Flexural strength (N/ } \\
\left.\mathrm{mm}^{2}\right)\end{array}$ & $\begin{array}{l}\text { Impact } \\
\text { strength } \\
(\mathrm{J} / \mathrm{m})\end{array}$ \\
\hline A1 & 285.74 & 0.23 & 215.79 & 242 \\
A2 & 324.20 & 0.18 & 335 & 139 \\
A3 & 354.51 & 0.16 & 325.46 & 72 \\
\hline
\end{tabular}




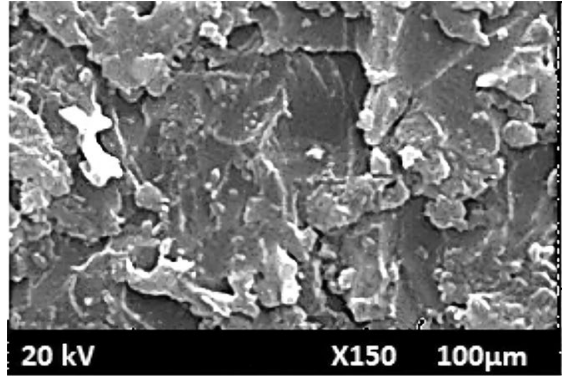

(a)

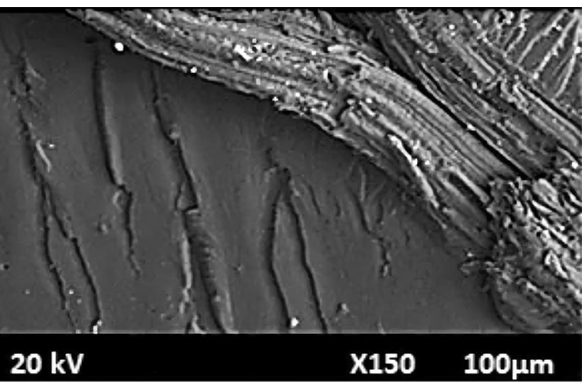

(b)

Fig. 3 SEM micrographs of fabricated coir fiber/carbon fiber/epoxy resin reinforced hybrid composite (a) without and (b) with $10 \%$ alkaline treatment [32]

has proven to be an efficient approach to manufacturing goods of good quality at a reasonably lower cost. The rudimentary concept of Taguchi's design technique is to enhance the product's quality through minimising the impact of the cause of variations without excluding it. In order to achieve the minimally sensitive output to the distinct sources of deviations, that can be done by optimising the various product/ process designs.

To perform the experiments, Taguchi proposed appropriately built experimental matrices called as OAs. Established on the several of input variables, their corresponding levels moreover, if any, interaction among them, the OAs are selected. To understand the nonlinear (curvature) relationships, a minimum of three levels of process parameters are needed [34]. Since the cutting process of laser is nonlinear and complex, three levels of each parameter were chosen for experimentation. Four control parameters have been considered in the current work, with three levels each.

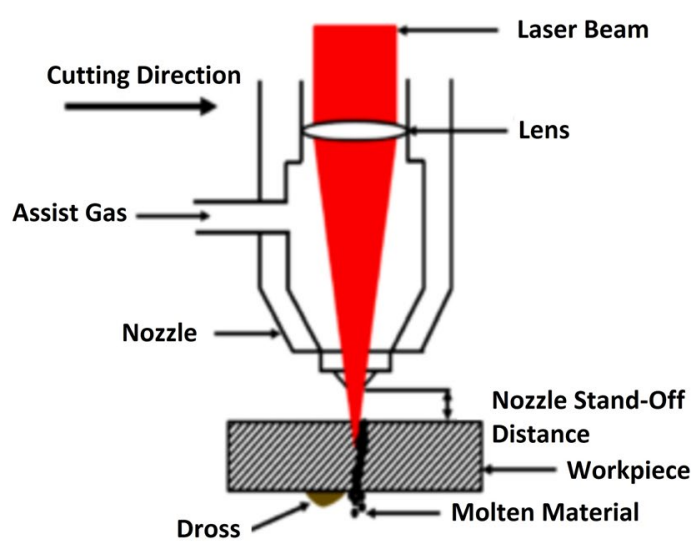

(a)

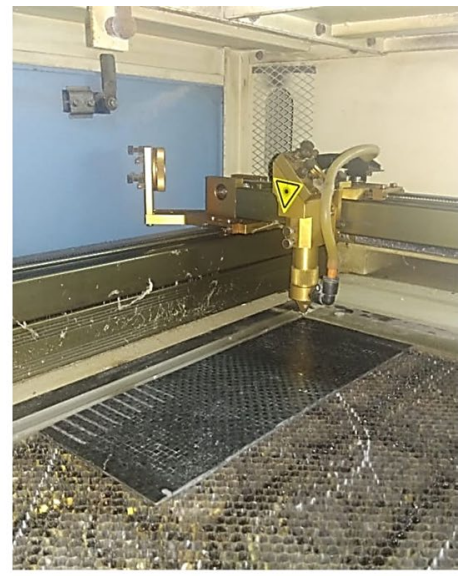

(b)

Fig. 4 (a) Schematic of $\mathrm{CO}_{2}$ laser processing, (b) details of the experimental set of laser system with specimen mounted on it [33] 
Experiments were carried out by using the simplest $\mathrm{L}_{9}$ OA [32, 35]. In Table 3, the numerical values of each level corresponding to these parameters of cutting is demonstrated.

Experiments are planned after choosing the parameters for laser cutting and their determined levels. The LBC of Coir fibre/carbon fibre/ epoxy resin reinforced hybrid composite sheets are carried out along a $40 \mathrm{~mm}$ long straight cut profile. The KT and the SR are considered as quality characteristics. Kerf widths are determined at five different positions on the top as well as bottom along the length of cut. Average values that give the width of top \& bottom kerf, respectively uses stereo optical microscope (Leica) with $10 \times$ magnification. In this analysis, SJ-series surface roughness testing rig delivered by Mitutoyo, Japan was used and the average values of five Arithmetical mean surface roughness $\left(R_{a)}\right.$ readings, the surface roughness tester $\left(R_{a}\right.$ values) calculated at five different locations of the cut edge surface showing the SR for that particular experimental run was presented. It is possible to calculate the Kerf taper $\left(^{\circ}\right)$ using the following equation:

$$
\mathrm{KT}=\frac{(\mathrm{TKW}-\mathrm{BKW}) \times 180}{2 \pi t}
$$

where, thickness of a composite sheet is ' $t$ ' in $\mathrm{mm}$. In Table 4, experimental data of the KT and SR with respect to respective investigative run have been demonstrated. Also, Table 5 shows the value of TKW \& BKW for each specimen.

\section{Modelling and Optimization Using RSM of Process Variables}

This method is a statistical and mathematical set of approach that is essential for modelling and evaluating engineering problems. The following procedure was followed in RSM: the appropriate choice of variables with important impacts, the selection of the relevant investigative design, the fitting of the required mathematical model, then the verification of the reliability of the equipped model and lastly the assessment of its predictive behaviour in relation to the experimental data [36, 37]. To explain the functional relationship among laser cutting variables and the response surface, there is a model of the second order form which is proposed. Generally, a response surface equation is specified as:

Table 3 Cutting variables \& their corresponding levels

\begin{tabular}{|c|c|c|c|c|}
\hline \multicolumn{2}{|c|}{ Cutting variables (Unit) } & \multicolumn{3}{|c|}{ Levels } \\
\hline & & \multirow{2}{*}{$\begin{array}{l}1 \\
2\end{array}$} & \multirow{2}{*}{$\begin{array}{l}2 \\
4\end{array}$} & \multirow{2}{*}{$\begin{array}{l}3 \\
6\end{array}$} \\
\hline A & Gas pressure $\left(\mathrm{N} / \mathrm{mm}^{2}\right)$ & & & \\
\hline $\mathrm{B}$ & Pulse width (ms) & 1.5 & 2 & 2.5 \\
\hline $\mathrm{C}$ & Pulse frequency $(\mathrm{Hz})$ & 5 & 10 & 15 \\
\hline $\mathrm{D}$ & Cutting speed $(\mathrm{mm} / \mathrm{s})$ & 7 & 9 & 11 \\
\hline
\end{tabular}




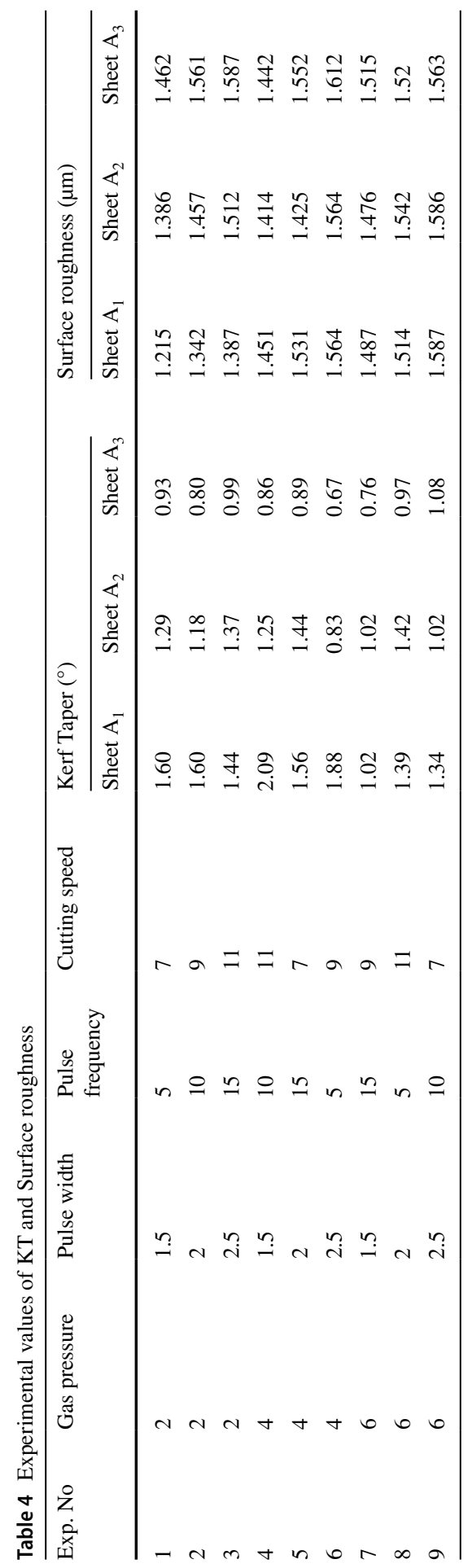


Table 5 Value of TKW and BKW for each specimen

\begin{tabular}{|c|c|c|c|c|c|c|}
\hline \multirow[t]{2}{*}{ S.no } & \multicolumn{2}{|l|}{$A_{1}$} & \multicolumn{2}{|l|}{$\mathbf{A}_{2}$} & \multicolumn{2}{|l|}{$\mathbf{A}_{3}$} \\
\hline & TKW & BKW & TKW & BKW & TKW & BKW \\
\hline 1 & 0.500 & 0.325 & 0.521 & 0.355 & 0.525 & 0.399 \\
\hline 2 & 0.536 & 0.378 & 0.561 & 0.375 & 0.501 & 0.361 \\
\hline 3 & 0.502 & 0.365 & 0.418 & 0.302 & 0.441 & 0.301 \\
\hline
\end{tabular}

where, all of the regression coefficients are designated as $\beta_{0} \beta \mathrm{i}, \beta \mathrm{ii}$, and $\beta \mathrm{ij}$ and the input variables as $\mathrm{x}_{\mathrm{i}}, \mathrm{x}_{\mathrm{i}}, \mathrm{x}_{\mathrm{i}} \mathrm{x}_{\mathrm{j}}$ that effect the responses. In addition, the established models have been tested using MINITAB version 18 to verify the model's competency by performing the analysis of variance (ANOVA). Also, a response optimizer is employed to optimise the quality characteristics for the optimization purpose.

\section{Results and Discussions}

\section{Kerf Taper Modelling Using RSM}

The non-significant terms were considered to match the quadratic model for the kerf taper by using backward elimination process. After extracting the non-significant terms, the final response equations of the kerf for different samples (A1, A2 \& A3) are found in uncoded form as follows:

\begin{tabular}{|c|c|c|}
\hline $\begin{array}{l}\text { Sample A1 } \\
\text { (RSM eq.) }\end{array}$ & Kerf taper $=$ & $\begin{aligned} \mathrm{KT}= & 1.773+0.000001 \text { Gas pressure } \\
& -0.7367 \text { Pulse width } \\
& +0.1277 \text { Pulse frequency } \\
& -0.2800 \text { Cutting speed } \\
& -0.000000 \text { Gas pressure } * \text { Gas pressure } \\
& +0.1800 \text { Pulse width } * \text { Pulse width } \\
& -0.007800 \text { Pulse frequency } \\
& * \text { Pulse frequency } \\
& +0.01750 \text { Cutting speed } * \text { Cutting speed }\end{aligned}$ \\
\hline $\begin{array}{l}\text { Sample A2 } \\
\text { (RSM eq.) }\end{array}$ & Kerf taper $=$ & $\begin{aligned} \mathrm{KT}= & 3.971-0.1183 \text { Gas pressure }+3.353 \text { Pulse width } \\
& -0.05300 \text { Pulse frequency } \\
& -1.273 \text { Cutting speed }+0.01083 \text { Gas pressure } * \text { Gas pressure } \\
& -0.8667 \text { Pulse width } * \text { Pulse width }+0.003133 \text { Pulse frequency } \\
& * \text { Pulse frequency } \\
& +0.07208 \text { Cutting speed } * \text { Cutting speed }\end{aligned}$ \\
\hline
\end{tabular}




\begin{tabular}{|c|c|c|}
\hline $\begin{array}{l}\text { Sample A1 } \\
\text { (RSM eq.) }\end{array}$ & Kerf taper $=$ & $\begin{aligned} \text { KT }= & 1.773+0.000001 \text { Gas pressure } \\
& -0.7367 \text { Pulse width } \\
& +0.1277 \text { Pulse frequency } \\
& -0.2800 \text { Cutting speed } \\
& -0.000000 \text { Gas pressure } * \text { Gas pressure } \\
& +0.1800 \text { Pulse width } * \text { Pulse width } \\
& -0.007800 \text { Pulse frequency } \\
& * \text { Pulse frequency } \\
& +0.01750 \text { Cutting speed } * \text { Cutting speed }\end{aligned}$ \\
\hline $\begin{array}{l}\text { Sample A3 } \\
\text { (RSM eq.) }\end{array}$ & Kerf taper $=$ & $\begin{aligned} \mathrm{KT}= & 5.033-0.2225 \text { Gas pressure }+0.1433 \text { Pulse width } \\
& +0.03833 \text { Pulse frequency } \\
& -0.9517 \text { Cutting speed }+0.02875 \text { Gas pressure } * \text { Gas pressure } \\
& -0.02000 \text { Pulse width } * \text { Pulse width }-0.001800 \text { Pulse frequency } \\
& * \text { Pulse frequency } \\
& +0.05250 \text { Cutting speed } * \text { Cutting speed }\end{aligned}$ \\
\hline
\end{tabular}

\section{Surface Roughness Modelling of using RSM}

The final response equations of surface roughness for different sample (A1, A2 \& A3) in uncoded form is found as follow:

\begin{tabular}{lll}
\hline Sample A1 & Surface roughness $=$ & SR $=0.04233+0.2402$ Gaspressure +0.3518 Pulsewidth \\
(RSM eq.) & +0.01193 Pulsefrequency +0.07707 Cuttingspeed \\
& -0.02332 Gas pressure $*$ Gas pressure \\
& -0.05587 Pulse width $*$ Pulse width \\
& -0.004192 Cuttingspeed $*$ Cuttingspeed
\end{tabular}

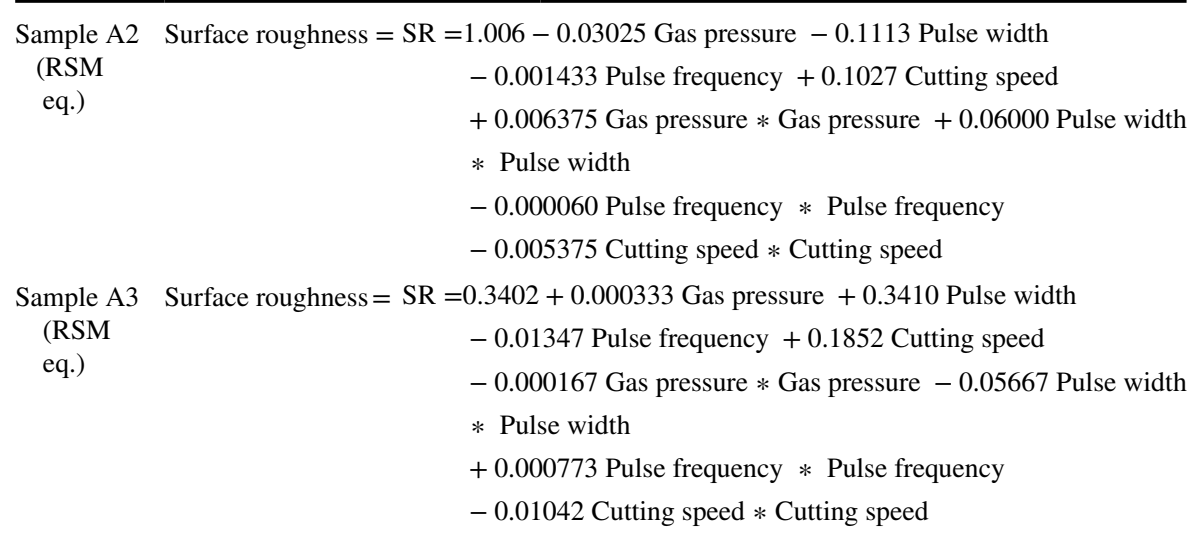




\section{Impact On Kerf Taper of Process Parameters}

\section{Impact On Kerf Taper of Process Parameters for Sample A1}

The surface response plot to analyse the variation of KT subjected to various cutting parameters for sample A1 is described in Fig. 5a-c. Impact of pulse frequency and pulse width w.r.t cutting speed on KT can be seen and it is seen that cutting speed is a dominant factor among all the cutting parameter which influences KT to great extent. It is demonstrated in Fig. 5a that KT is phenomenally increased with respect to cutting speed. Also, certain reduction in KT is observed when pulse frequency is decreased. Moreover, in Fig. 5b it is clearly shown that the KT experiences downfall with increasing pulse width.

However, in Fig. 5c effect of gas pressure is also described; upon increasing gas pressure decrease in KT is observed here again with proliferating cutting speed KT is raised. When analysing gas pressure w.r.t pulse width and pulse frequency, it is noticed that KT is reduced with increase pulse frequency and KT experiences slight variation with increase of pulse width.

a

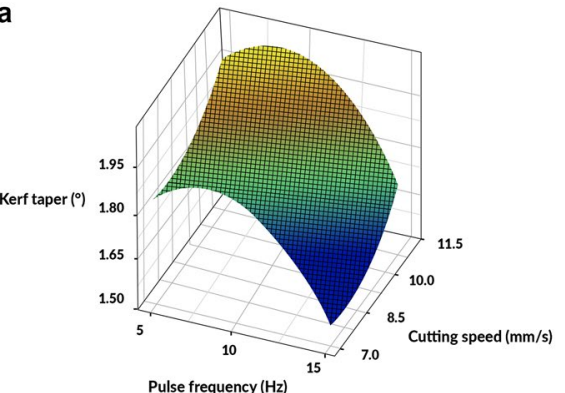

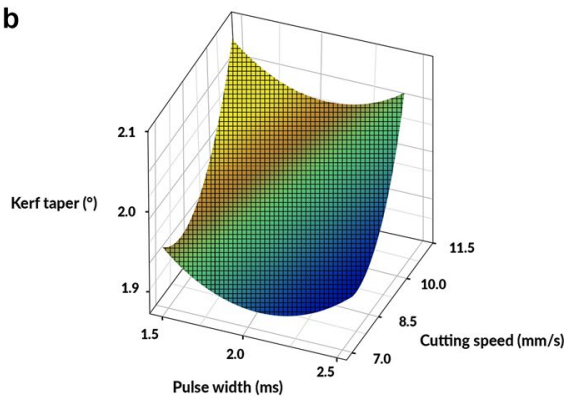

b

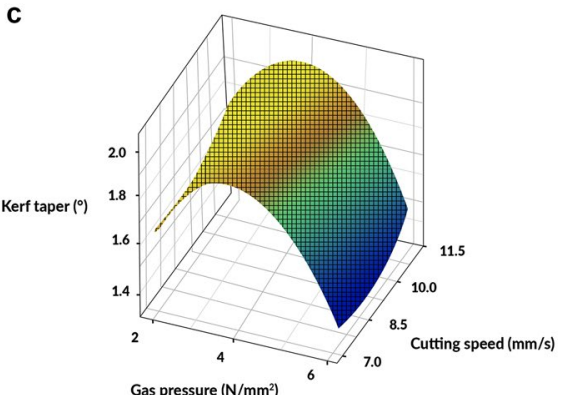

Fig. 5 (a) Variation exhibiting surface plot of kerf taper against the cutting speed and pulse frequency and (b) against the pulse width and cutting speed. (c) Variation exhibiting Surface plot of kerf taper against cutting speed and gas pressure (a-c): Impact on KT of process parameters for sample A1 


\section{Impact On Kerf Taper of Process Parameters for Sample A2}

The surface response plot to analyse the variance of the KT with regard to various cutting variables for sample A2 is shown in Figs. 6a-c. It is noticed that with rise in cutting speed, KT decreases but it is raised with rise in pulse frequency. With proliferating pulse width, KT decreases. Moreover, with increase in gas pressure, kerf taper decreases.

Figure $6 \mathrm{a}$ demonstrates that $\mathrm{KT}$ is increased with respect to pulse frequency. Also, slight reduction in KT is observed when pulse width is increased. Further, in Fig. $6 \mathrm{~b}$ it is clearly shown that the KT experiences sudden rise with increasing cutting speed and is decrease with raised gas pressure. However, KT is raised with rise in pulse frequency similar trends were seen by Gadallah and Abdu [38] while performing laser cutting of 316-LS steel.

In Fig. 6c it is clearly shown that the KT experiences downfall with increasing pulse width. Furthermore, when concluding effect of increased gas pressure, KT is increased with rise in pulse frequency but experiences downfall with growth of pulse width.

a

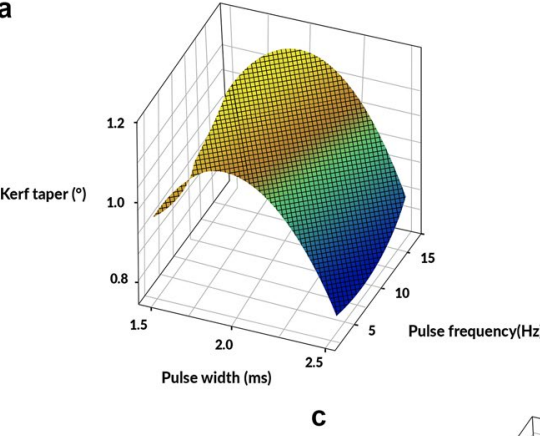

C b

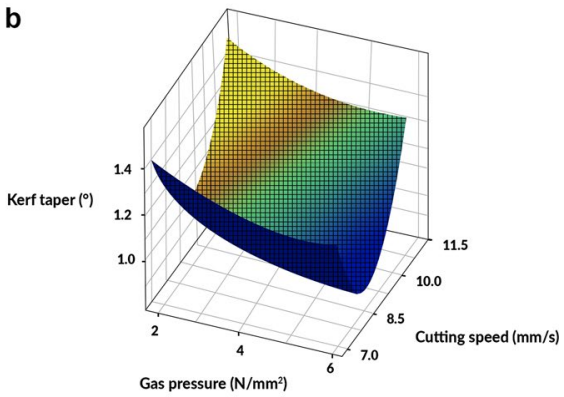

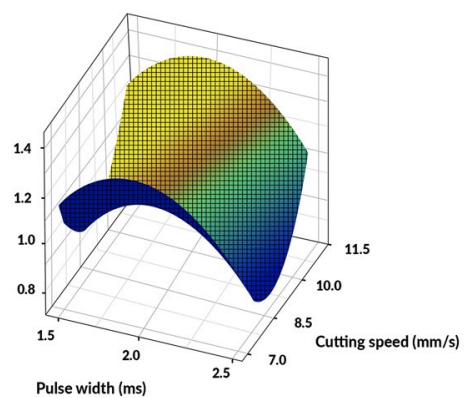

Fig. 6 (a) Variation exhibiting surface plot of kerf taper against pulse frequency and pulse width and 6 (b) against cutting speed and gas pressure. (c) Variation exhibiting Surface plot of kerf taper against pulse width and cutting speed (a-c) Impact on KT of process parameters for sample A2 


\section{Impact On Kerf Taper of Process Parameters for Sample A3}

Figure $7 \mathrm{a}-\mathrm{c}$ demonstrates the surface response plot to analyse the variation of KT subjected to various cutting variables for sample A3. It is noticed that with proliferating cutting speed and pulse frequency KT decreases. With proliferating pulse width, KT increases. Moreover, with increase in gas pressure, kerf taper decreases.

It is illustrated in Fig. 7a that KT is increased with the rise in cutting speed as well as gas pressure, similar trends were seen by Gadallah and Abdu [38] while performing laser cutting of 316-LS steel. It is revealed from Fig. 7b KT is increased with increase in pulse frequency and similarly with raised gas pressure.

Further, in Fig. 7c it is clearly indicated that the KT experiences rise with increase of pulse width and similar trend is observed with increased gas pressure. While examining the influence of cutting speed on KT, it is concluded that gas pressure, pulse width \& pulse frequency is increased simultaneously.

The high-magnified, SEM micro-images were obtained with different laser cutting variables after the laser-cutting of Coir fibre/carbon fibre/epoxy resin reinforced hybrid composite as revealed in the Fig. 8a, b which shows the peeling-off structure of coir and carbon fibers at the top side during laser cut and narrow HAZ at the top surface. This is because the heat accumulated by the coir and carbon fibers is strong
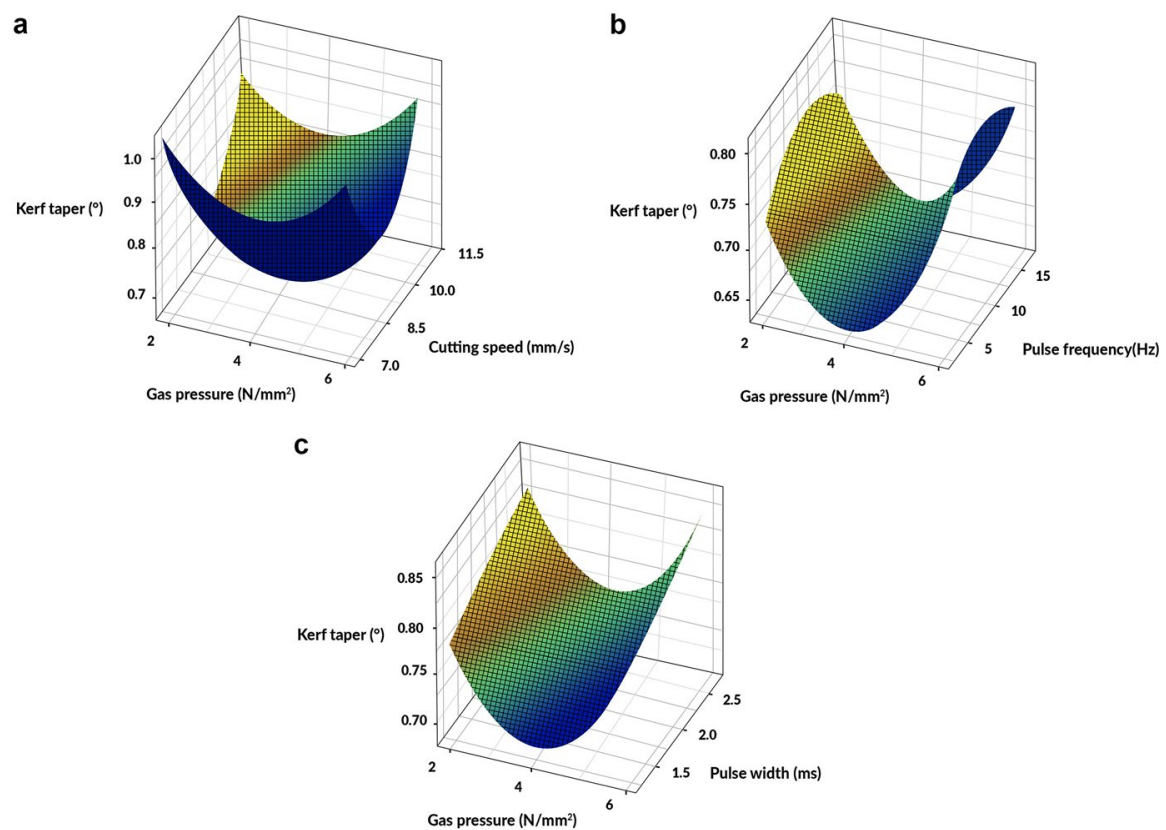

Fig. 7 (a) Variation exhibiting surface plot of kerf taper against gas pressure and cutting speed; and (b) against pulse frequency and gas pressure. (c) Variation exhibiting Surface plot of kerf taper against pulse width and gas pressure (a-c) Impact on KT of process parameters for sample A3 
enough to decompose polymer matrix (Epoxy) without burning of fibers. However, at bottom surface, less HAZ and reduced fibre out is revealed.

Irregular shapes on the bottom side of the cut have also been indicated. These types were formed due to the difference between coir fibre, carbon fibre and epoxy matrix in thermal properties. This is due to the transmission of heat to the polymer matrix by the fibre filaments. Epoxy has a vicious nature, so it's quite difficult to eject as it melts, and heat accumulation occurs at the bottom of the cut and results in droplet deposition and thermal degradation as shown in Fig. 9a, b.

\section{Impact On Surface Roughness of Process Parameters}

\section{Impact On Surface Roughness of Process Parameters for Sample A1}

The surface response plot to analyse the variation of surface roughness with reference to various cutting variables for sample A3 is shown in Figs. 8a-f. It is noticed that with the rise in pulse frequency, surface roughness increases whereas it is declined with rise in cutting speed. With proliferating pulse width, surface roughness decreases whereas it is reduced with increase in pulse frequency. Moreover, with increase in gas pressure, surface roughness decreases. It is demonstrated in Fig. 10a that SR is phenomenally increase with increase in cutting speed and pulse frequency similar trends were reported by Gadallah and Abdu [38] while performing laser cutting of stainless steel (316L). Moreover, in Fig. 10b it is clearly shown that the SR is significantly raised with increasing cutting speed and pulse width.

It is illustrated in Fig. 10c that SR is increased with increase in pulse frequency as well as with pulse width. Also, SR experiences sudden rise with increasing gas pressure and cutting speed. Further, it is concluded that effect of gas pressure on SR are similar for cutting speed and pulse frequency, as gas pressure is increased along with rise in cutting speed and pulse frequency slightly increase in SR is observed.

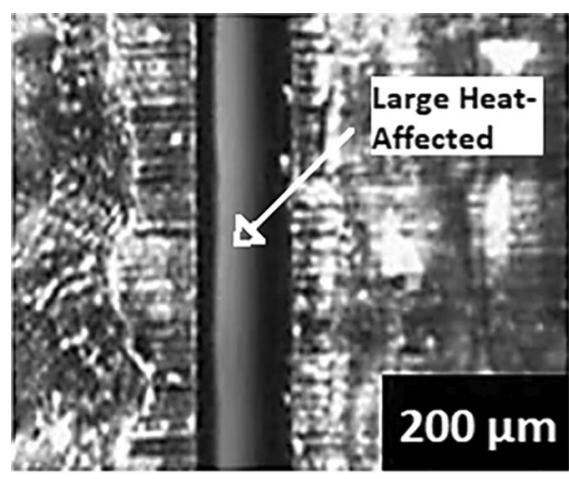

(a)

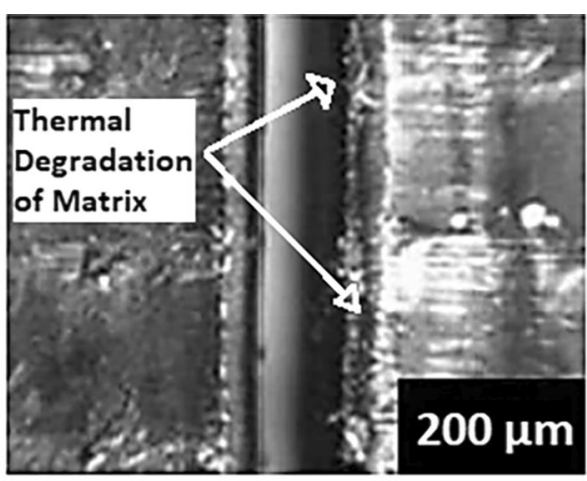

(b)

Fig. 8 (a-b) Top-view of the laser-cutting kerf of Coir fibre/carbon fibre/epoxy resin reinforced hybrid composite at various pulse-frequency and number of passes 


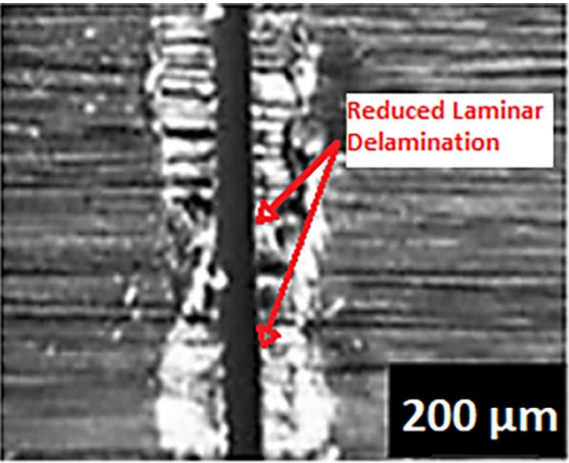

(a)

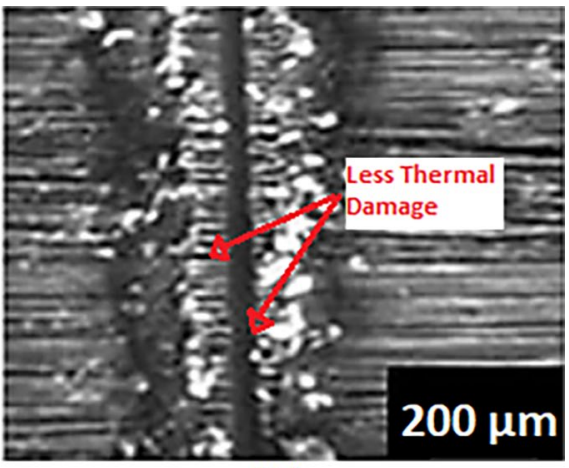

(b)

Fig. 9 (a-b) Bottom view of the laser-cutting kerf of Coir fibre/carbon fibre/epoxy resin reinforced hybrid composite at various pulse-frequency and number of passes

\section{Impact on Surface Roughness of process parameters for sample A2}

Figure 11a-c illustrates the surface response plot to evaluate the variation of surface roughness with reference to various cutting variables for sample A2. It is noticed

a

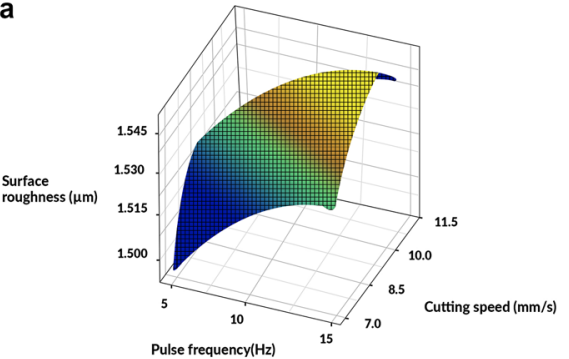

b

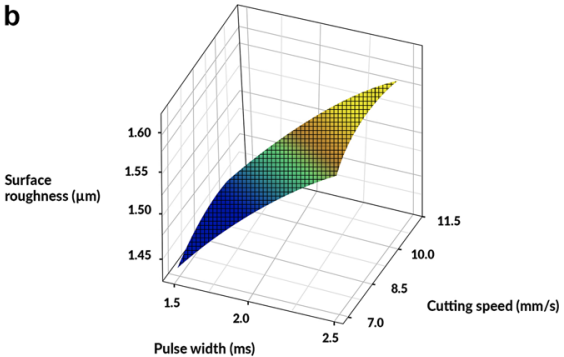

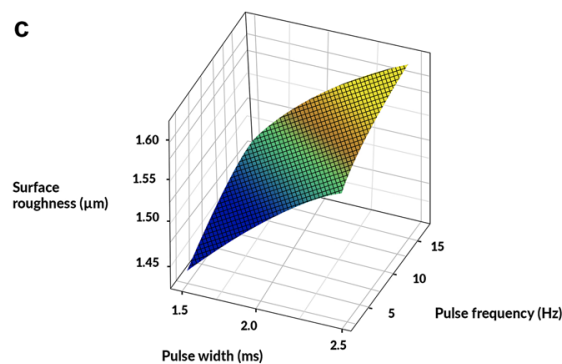

Fig. 10 (a) Variation exhibiting surface plot of SR against cutting speed and pulse frequency; and10 (b) against cutting speed and pulse width. (c) Variation exhibiting surface plot of SR against pulse width and pulse frequency. (a-c): Impact on SR of process parameters for sample A1 
that with raised pulse frequency and cutting speed, SR declines. With proliferating pulse frequency and pulse width, SR increases whereas it is reduced with growth in pulse frequency. Moreover, with increase in gas pressure, SR increases.

It is demonstrated in Fig. 11a that SR is significantly declined with rise in pulse frequency but rise with increase in cutting speed. Moreover, SR is raised with increasing pulse width and cutting speed. It is illustrated in Fig. 11b that SR is increased with increase in pulse frequency as well as with pulse width.

Also, similar trend is observed in Fig. 11c as it is clearly shown that the SR experiences sudden rise with increasing gas pressure and cutting speed. While concluding effect of gas pressure w.r.t pulse frequency and pulse width SR is significantly increased.

\section{Impact On Surface Roughness of Process Parameters for Sample A3}

Figure $12 \mathrm{a}-\mathrm{c}$ displays the surface response plot to analyse the variation of SR with reference to various cutting variables for sample A3. It is noticed that with growth in cutting speed, SR decreases. With proliferating pulse frequency and pulse width, $\mathrm{SR}$ increases whereas it is reduced with raising in pulse frequency. Moreover, with increasing gas pressure, SR decreases.

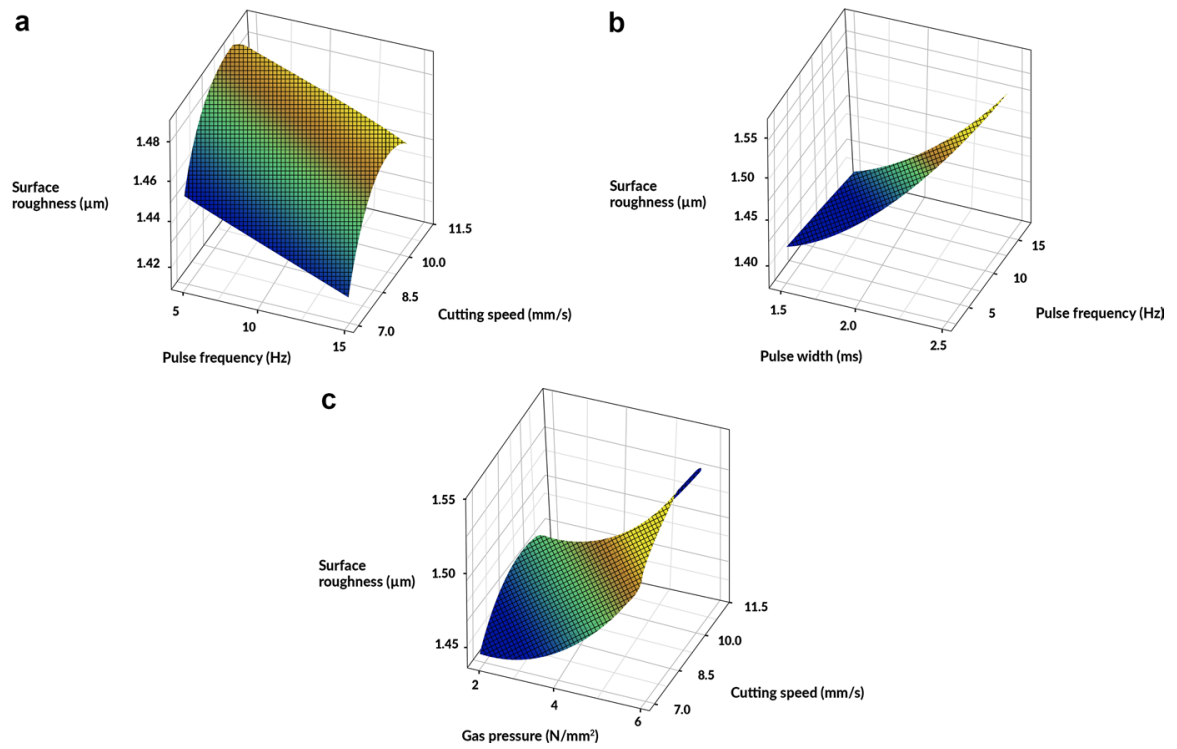

Fig. 11 (a) Variation exhibiting surface plot of SR against cutting speed and pulse frequency; and 11 (b) against pulse frequency and pulse width. (c) Variation exhibiting Surface plot of SR against gas pressure and cutting speed (a-c): Impact of process parameters on SR for sample A2 
It is demonstrated in Fig. 12a that SR is significantly decreased with increasing cutting speed but rise with increasing pulse frequency. Also, it is observed SR is significantly raised with increasing pulse width and cutting speed. Figure $12 \mathrm{~b}$ demonstrates that SR experiences slight downfall with raising gas pressure and SR decreases with increase in cutting speed, similar trends were reported by Kotadiya and Pandya while laser cutting of SS-304 [39].

It is shown in Fig. 12c that SR is phenomenally increased with rise in pulse frequency and slightly declines with increased gas pressure. Further, it is noticed that the SR experiences rise with rising of pulse frequency as well as pulse width and SR stays constant with increasing gas pressure.

\section{Optimization of response parameters}

The predicted optimum parameter settings for KT and SR are reflected in Tables 3, 4 and 5 revealed that the optimal laser cutting parameter levels as depicted from the RSM multi-optimizer to the kerf-taper are: gas-pressure at $\left(6 \mathrm{~N} / \mathrm{mm}^{2}\right)$, pulsewidth at $(2.04 \mathrm{~ms})$, cutting-speed at $(8.01 \mathrm{~mm} / \mathrm{min})$ and pulse-frequency $(15 \mathrm{~Hz})$ for sample A1. For sample A2, gas-pressure at $\left(5.47 \mathrm{~N} / \mathrm{mm}^{2}\right)$, pulse-width at $(2.5 \mathrm{~ms})$, cutting-speed at $(8.81 \mathrm{~mm} / \mathrm{min}$.) and pulse-frequency $(8.43 \mathrm{~Hz})$. For sample A3,

a

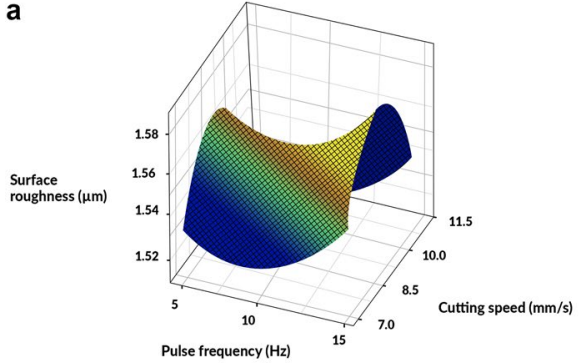

b

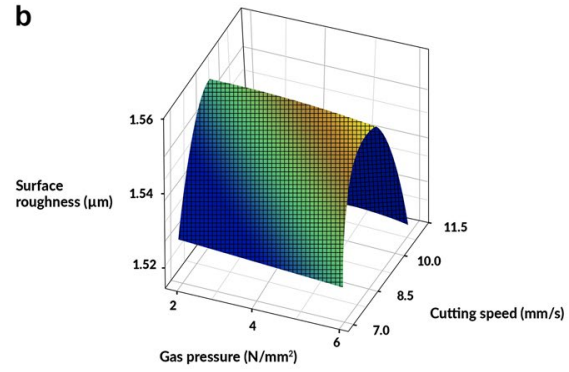

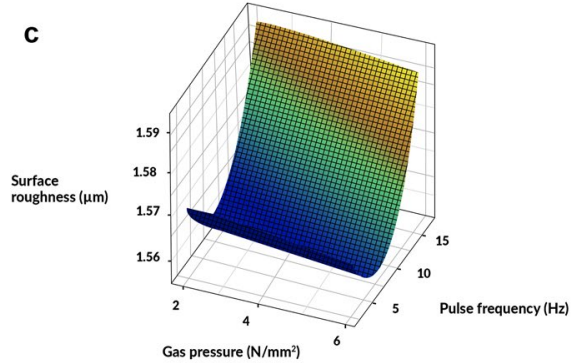

Fig. 12 (a) Variation exhibiting surface plot of SR against cutting speed and pulse frequency; and 12 (b) against gas pressure and cutting speed. (c) Variation exhibiting Surface plot of SR against pulse frequency and gas pressure. (a-c): Impact on SR of process parameters for sample A3 
Table 6 Optimized input process parameters for Kerf taper

\begin{tabular}{llllll}
\hline Sample & Response & \multicolumn{2}{l}{ Optimize variables } & \\
\cline { 3 - 6 } & & $\begin{array}{l}\text { Gas pressure } \\
\left(\mathrm{N} / \mathrm{mm}^{2}\right)\end{array}$ & $\begin{array}{l}\text { Pulse width } \\
(\mathrm{ms})\end{array}$ & $\begin{array}{l}\text { Pulse fre- } \\
\text { quency } \\
(\mathrm{Hz})\end{array}$ & $\begin{array}{l}\text { Cutting speed } \\
(\mathrm{mm} / \mathrm{s})\end{array}$ \\
\hline $\mathrm{A}_{1}$ & $\mathrm{KT}$ & 6 & 2.04 & 15 & 8.01 \\
$\mathrm{~A}_{2}$ & & 5.47 & 2.5 & 8.43 & 8.81 \\
$\mathrm{~A}_{3}$ & 3.85 & 1.5 & 5 & 9.06 \\
\hline
\end{tabular}

gas-pressure at $\left(3.85 \mathrm{~N} / \mathrm{mm}^{2}\right)$, pulse-width at $(1.5 \mathrm{~ms})$, cutting-speed at $(9.06 \mathrm{~mm} /$ min). and pulse-frequency $(5 \mathrm{~Hz})$.

Tables 6 and 7 unveiled that the optimal laser cutting parameter levels as portrayed from the RSM multi-optimizer to the surface-roughness are: gas-pressure at $\left(2 \mathrm{~N} / \mathrm{mm}^{2}\right)$, pulse-width at $(1.5 \mathrm{~ms})$, cutting-speed at $(7 \mathrm{~mm} / \mathrm{min})$ and pulsefrequency $(5 \mathrm{~Hz})$ for sample A1. For sample A2, gas-pressure at $\left(2.36 \mathrm{~N} / \mathrm{mm}^{2}\right)$, pulse-width at $(1.5 \mathrm{~ms})$, cutting-speed at $(7 \mathrm{~mm} / \mathrm{min})$ and pulse-frequency $(15 \mathrm{~Hz})$ For sample A2, gas-pressure at $\left(6 \mathrm{~N} / \mathrm{mm}^{2}\right)$, pulse-width at $(1.5 \mathrm{~ms})$, cutting-speed at $(11 \mathrm{~mm} / \mathrm{min})$ and pulse-frequency $(8.73 \mathrm{~Hz})$. A mathematical simulation of laser beam cutting of CFRP was carried out by Tomomasa et al., to recognise the process of HAZ generation in order to enhance the efficiency of laser CFRP cutting. A new measurement model has been developed to understand the influence of decomposition as well as combustion of each component of CFRP. Eventually, the measurement model was checked in comparison with the experimental results as well as simulation and moreover, the deleterious implications of laser irradiation within CFRP has been exhibited in detailed-manner [13].

For the cutting of CFRP composites, Leone et al. [15] utilised a Nd: YAG $150 \mathrm{~W}$ laser pulsed type. Results revealed that the precise selection of parameters for laser cutting can minimise the HAZ and KT.

Furthermore, it is also observed during the laser cutting of the coir fibre/carbon fibre/epoxy hybrid composite from the SEM images of the cut edge surface in Fig. 13a, b that the heat conduction characteristics of coir fibre, carbon fibre and epoxy resin are also accountable for improper hybrid composite laser cutting. Matrix Crack and Matrix recession can also be seen on the surface of the hybrid

Table 7 Optimized input process parameters for Surface roughness

\begin{tabular}{|c|c|c|c|c|c|}
\hline \multirow[t]{2}{*}{ Sample } & \multirow[t]{2}{*}{ Response } & \multicolumn{4}{|c|}{ Optimize variables } \\
\hline & & $\begin{array}{l}\text { Gas pressure } \\
\left(\mathrm{N} / \mathrm{mm}^{2}\right)\end{array}$ & $\begin{array}{l}\text { Pulse width } \\
\text { (ms) }\end{array}$ & $\begin{array}{l}\text { Pulse fre- } \\
\text { quency } \\
(\mathrm{Hz})\end{array}$ & $\begin{array}{l}\text { Cutting speed } \\
(\mathrm{mm} / \mathrm{s})\end{array}$ \\
\hline $\mathrm{A}_{1}$ & SR & 2 & 1.5 & 5 & 7 \\
\hline $\mathrm{A}_{2}$ & & 2.36 & 1.5 & 15 & 7 \\
\hline $\mathrm{A}_{3}$ & & 6 & 1.5 & 8.73 & 11 \\
\hline
\end{tabular}




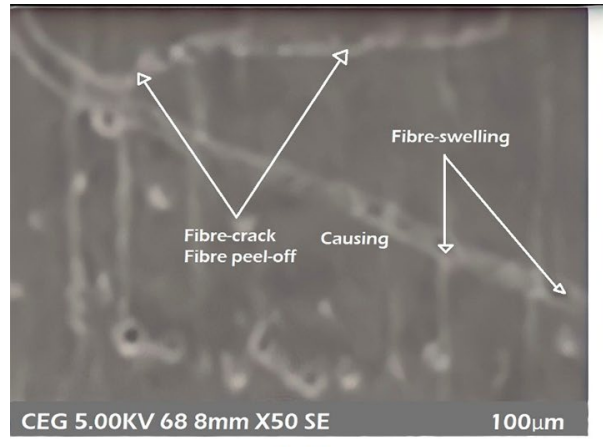

(a)

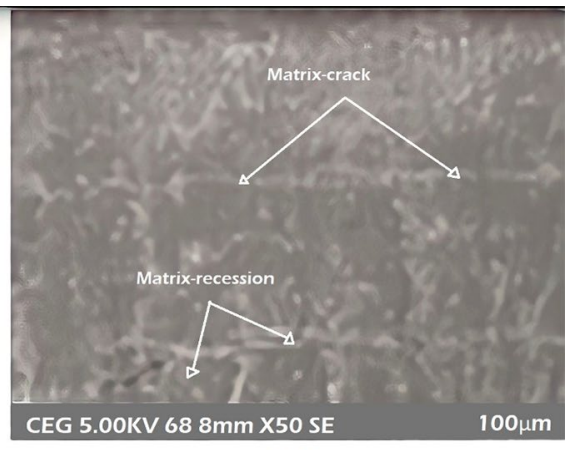

(b)

Fig. 13 (a-b) Effect of raising speed in multi-pass machining on delaminating of Coir fibre/carbon fibre/ epoxy resin reinforced hybrid composite at various cutting-speed and no. of passes using laser-machining parameters

composite, Matrix recession happens due to different thermo-physical properties of the fibers \& matrix, when extracted at different speeds.

Likewise, Gautam and Mishra [18] carried out the cutting through laser of $1.60 \mathrm{~mm}$ thick BFRC sheets for the purpose of optimise numerous variables includes, kerf deviation, KT and kerf width by employed a firefly-based approach, a multi-objective optimization approach. Outcomes observed that the width of kerf and KT were indispensably affected by lamp current. The results usually noticed that all characteristics of quality of kerf have a marginal effect on the frequency of pulses.

\section{Conclusions}

In this research work, modelling and parameter optimization while pulsed $\mathrm{CO}_{2}$ laser cutting of fabricated coir fibre/carbon fibre/epoxy hybrid composite sheet were conducted using RSM. Here, the composite material used is completely novel one and till date no research has caried out on machining on this hybrid composite. So, the combination of Carbon fiber (woven type) and coir fiber was explored for the first time. Similarly, Vacuum assisted hand lay-up/ vacuum bagging method is employed for the first time to fabricate coir/carbon fiber together to form a hybrid composite. In predicting the response via mathematical modeling, the RSM method is much more encouraging. RSM is being used to obtain the points of the experiment and analyze the factors in the evaluation process that can play a critical role. Also, we are approaching towards optimal solution, other authors have used three process parameters rather than four process parameters and two response parameters that we have used and studied the contemplate. The current study draws the following conclusions. 
a. The fibre laser can cut coir fibre/carbon fibre/epoxy hybrid composite sheet and greater surface quality on cut surfaces can be obtained easily with optimal parameter settings.

b. For SR and KT, the established second order response surface model has been found to be appropriate. For developed models, it is observed that the combination of regression \& linear, also square effects of laser cutting variables are relevant.

c. Morphological analysis revealed the heat accumulated by the coir and carbon fibers is strong enough to decompose polymer matrix without burning of fibers.

d. Optimal laser cutting parameter levels are found from the RSM multi-optimizer to the kerf taper as: gas pressure at $\left(6 \mathrm{~N} / \mathrm{mm}^{2}\right)$, pulse width at (2.04), cutting speed at $(8.01 \mathrm{~mm} / \mathrm{min})$ and pulse frequency $(15 \mathrm{~Hz})$ for sample A1. For sample A2, gas pressure at $(5.47 \mathrm{~N} / \mathrm{mm} 2)$, pulse width at $(2.5)$, cutting speed at $(8.81 \mathrm{~mm} /$ min). and pulse frequency $(8.43 \mathrm{~Hz})$ For sample A3, gas pressure at $(3.85 \mathrm{~N} /$ $\left.\mathrm{mm}^{2}\right)$, pulse width at $(1.5)$, cutting speed at $(9.06 \mathrm{~mm} / \mathrm{min})$. and pulse frequency (5 Hz).

e. Optimal laser cutting parameter levels are found from the RSM multi-optimizer to the surface roughness as: gas pressure at $\left(2 \mathrm{~N} / \mathrm{mm}^{2}\right)$, pulse width at (1.5), cutting speed at $(7 \mathrm{~mm} / \mathrm{min})$ and pulse frequency $(5 \mathrm{~Hz})$ for sample A1. For sample A2, gas pressure at $\left(2.36 \mathrm{~N} / \mathrm{mm}^{2}\right)$, pulse width at $(1.5)$, cutting speed at $(7 \mathrm{~mm} / \mathrm{min})$ and pulse frequency $(15 \mathrm{~Hz})$ For sample A2, gas pressure at $\left(6 \mathrm{~N} / \mathrm{mm}^{2}\right)$, pulse width at $(1.5)$, cutting speed at $(11 \mathrm{~mm} / \mathrm{min})$ and pulse frequency $(8.73 \mathrm{~Hz})$.

f. For other materials of similar kinds, this kind of analysis can also be effectively carried out. The variables may be changed with whichever, a higher cut rate or even a better-quality cut, probably depending upon the type of operation (roughing or a finishing).

g. The mechanical test results of the manufactured Coir fiber/Carbon fiber/Epoxy resin hybrid composite revealed that the idea of using two distinct fibers is feasible for the application of the helmet shell, Sports goods, flooring, and roofing. There is, however, a potential for optimizing the volume fraction of natural fibers as reinforcements to attain the improved mechanical properties [32].

Open Access This article is licensed under a Creative Commons Attribution 4.0 International License, which permits use, sharing, adaptation, distribution and reproduction in any medium or format, as long as you give appropriate credit to the original author(s) and the source, provide a link to the Creative Commons licence, and indicate if changes were made. The images or other third party material in this article are included in the article's Creative Commons licence, unless indicated otherwise in a credit line to the material. If material is not included in the article's Creative Commons licence and your intended use is not permitted by statutory regulation or exceeds the permitted use, you will need to obtain permission directly from the copyright holder. To view a copy of this licence, visit http://creativecommons.org/licen ses/by/4.0/.

\section{References}

1. Santulli, C.: Mechanical and impact damage analysis on carbon/natural fibers hybrid composites: a review. Materials 12(517), 1-17 (2019) 
2. Gautam, G.D., Pandey, A.K.: Pulsed Nd: YAG laser beam drilling: A review. Opt. Laser Technol. 100, 183-215 (2018)

3. Lau, W.S., Lee, W.B., Pang, S.Q.: Pulsed Nd: YAG laser cutting of carbon fibre composite materials. Annals of the CIRP. 39(2), 179-182 (1990)

4. Ilio, A.D., Tagliaferri, V.: Cutting mechanism in drilling of aramid. International journal of machine tools and manufacturing. 31(2), 155-165 (1990)

5. Mathew, J., Goswami, G.L., Ramakrishnan, N., Naik, N.K.: Parametric studies on pulsed Nd_: YAG laser cutting of carbon fibre reinforced plastic composites. J. Mater. Process. Technol. 90, 198-203 (1999)

6. Ilio, A.D., Tagliaferri, V.: Machining parameters and cut quality in laser cutting of aramid fibre reinforced plastics. Mat. Manuf. Process. 5(4), 591-608 (1990)

7. Fenoughty, K.A., Jawaid, A., Pashby, I.R.: Machining of advanced engineering materials using traditional and laser techniques. J. Mat. Proc. Tech. 42, 391-400 (1994)

8. Verma, N., Zafar, S., Pathak, H.: Investigations on thermal damage and surface roughness of laser beam machined nano-hydroxyapatite UHMWPE composites. Manufacturing Letters 25, 81-87 (2020)

9. Elsheikh, A.H., Deng, Wu., Showaib, E.A.: Improving laser cutting quality of polymethylmethacrylate sheet: experimental investigation and optimization 9(2), 1325-1339 (2020)

10. Ohkuboa, T., Tsukamotob, M., Sato, Y.: Numerical Simulation of Laser Beam Cutting of Carbon Fiber Reinforced Plastics Physics. Procedia 56, 1165-1170 (2014)

11. Yilbas, B.S., Shaukat, M.M., Ashraf, F.: Laser cutting of various materials: Kerf width size analysis and life cycle assessment of cutting process. Opt. Laser Technol. 93, 67-73 (2017)

12. Leone, C., Genna, S.: Heat affected zone extension in pulsed Nd: YAG laser cutting of CFRP. Composites Part B 201(140), 174-182

13. Cenna, A., Mathew, P.: Analysis and prediction of laser cutting parameters of fibre reinforced plastics (FRP) composite materials. Int. J. Mach. Tools Manuf. 42, 105-113 (2002)

14. Gautam, G.D., Pandey, A.K.: Teaching Learning Algorithm based Optimization of Kerf Deviations in Pulsed Nd: YAG Laser Cutting of Kevlar-29 Composite Laminates. Infrared Phys. Technol. 89, 203-217 (2017)

15. Gautam, G.D., Mishra, D.R.: Firefly algorithm-based optimization of kerf quality characteristics in pulsed Nd: YAG laser cutting of basalt fiber reinforced composite. Composites Part-B 176, 107340 (2019)

16. Thawari, G., Sundar J.K.S, Sundararajan G., Joshi S.V.: Influence of process parameters during pulsed Nd: YAG laser cutting of nickel-base superalloys. J. Mater. Process Technol.170, 229-239 (2005)

17. Rao, R., Yadava, V.: Multi-objective optimization of Nd-YAG laser cutting of thin super alloy sheet using grey relational analysis with entropy measurement. Opt. Laser Technology 41, 922-930 (2009)

18. Sharma, A., Yadava, V.: Modelling and optimization of cut quality during pulsed Nd: YAG laser cutting of thin Al-alloy sheet for straight profile. Opt. Laser Technology 44, 159-168 (2012)

19. Adalarasan, R., Santhanakumar, M., Rajmohan, M.: Optimization of laser cutting parameters for

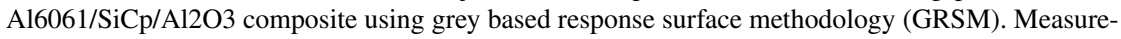
ment 73, 596-606 (2015)

20. Kurt, M., Kaynak, Y., Bagci, E., Demirer, H.: Dimensional analyses and surface quality of the laser cutting process for engineering plastics. Int. J. Adv. Manuf. Technology 41(3-4), 259-267 (2009)

21. Eltawahni, N.S., Rossini, M., Dassisti, K., Alrashed, T.A., Aldaham, K.Y., Benyounis, A.G.: Olabi, Evaluation and optimization of laser cutting parameters for plywood materials. Opt. Laser Eng. 51(9), 1029-1043 (2013)

22. Salonitis, K., Chryssolouris, G.: an investigation of quality in $\mathrm{CO} 2$ laser cutting of aluminium. CIRP J. Manuf. Sci. Technology 2(1), 61-69 (2009)

23. Choudhury, I.A., Shirley, S.: Laser cutting of polymeric materials: An experimental investigation. Opt. Laser Technol. 42, 503-508 (2010)

24. Davim, J.P., Barricas, N., Conceicao, M., Oliveira, C.: some experimental studies on $\mathrm{CO}_{2}$ laser cutting quality of polymeric materials. J. Mater. Process. Technol. 198(1-3), 99-104 (2008) 
25. Davim, J.P., Oliveira, C., Barricas, N., Conceicao, M.: Evaluation of cutting quality of PMMA usingCO2 lasers. Int. J. Adv. Manuf. Technol. 35(9-10), 875-879 (2008)

26. Abbas, A.T., Pimenov, D.Y., Erdakov, I.N., Mikolajczyk, T., Soliman, M.S., El Rayes, M.M.: Optimization of cutting conditions using artificial neural networks and the Edgeworth-Pareto method for $\mathrm{CNC}$ face-milling operations on high-strength grade-H steel. The International Journal of Advanced Manufacturing Technology 105, 2151-2165 (2019)

27. Khan A.M., Jamil M., Mia M., Pimenov D.Y., Gasiyarov V.R., Gupta M.K., He N.: Multi-Objective Optimization for Grinding of AISI D2 Steel with Al2O3 Wheel under MQL: Materials 11, 2269 (2018). https://doi.org/10.3390/ma11112269

28. Pimenov D.Y., Abbas A.T., Gupta M.K., Erdakov I.N., Soliman MS El Rayes M.M.: Investigations of surface quality and energy consumption associated with costs and material removal rate during face milling of AISI 1045 steel. Int. J. Adv. Manuf. Technol. 107, 3511-3525 (2020)

29. Gautam, G., Mishra, D.R.: Evaluation of Geometrical Quality Characteristics in Pulsed Nd: YAG Laser Cutting of Kevlar-29/Basalt Fiber Reinforced Hybrid Composite Using Grey Relational Analysis Based on Genetic Algorithm. FME Transactions. 47, 560-575 (2019). https://doi.org/10.5937/ fmet1903560G

30. Yusuff, M., Sarifuddin, N., Ahmad, Z.: Properties, M., of Woven Carbon Fiber, Kenaf Fabric Reinforced Epoxy Matrix Hybrid Composites. Malaysian Journal of Microscopy 15, 10-16 (2019)

31. Systems, S.P.: Guide to composites [CD-ROM]. Structural Polymer Systems Limited, Isle of Wight, United Kingdom (2001)

32. Singh, Y., Singh, J., Sharma, S., Lam, T.D., Nguyen, D.N.: Fabrication and characterization of coir/ carbon fiber reinforced epoxy-based hybrid composite for helmet shells and sports-good applications: influence of fiber surface modifications on the mechanical, thermal and morphological properties. J. Market. Res. 9(6), 15593-15603 (2020)

33. Kumar, D., Gururaja, S.: Investigation of hole quality in drilled Ti/CFRP/Ti laminates using $\mathrm{CO} 2$ laser. Opt. Laser Technol. 126, 106130 (2020)

34. Phadke, M.S.: Quality engineering using robust design. Prentice-Hall, Englewood Cliffs, New Jersey (USA) (1989)

35. Ross, P.J.: Taguchi techniques for quality engineering. Tata McGraw-Hill Publishing Company Limited, New Delhi (India) (1996)

36. Montgomery, D.C.: Design and analysis of experiments, 7th edn. Willy India Private Ltd., Arizona State University (2009)

37. Bezerra, M.A., Santelli, R.E., Oliveira, E.P., Villar, L.S., Escaleira, L.A.: Response surface methodology (RSM) as a tool for optimization in analytical chemistry. Talanta 76, 965-977 (2008)

38. Gadallah, M.H., Abdu, H.M.: Modeling and optimization of laser cutting operations. Manuf. Rev. 2(20) (2015)

39. Kotadiya, D.J., Pandya, D.H.: Parametric analysis of laser machining with response surface method on SS-304. Procedia Technol. 23, 376-382 (2016)

Publisher's Note Springer Nature remains neutral with regard to jurisdictional claims in published maps and institutional affiliations.

\section{Authors and Affiliations}

\section{Yadvinder Singh ${ }^{1} \cdot$ Jujhar Singh ${ }^{2} \cdot$ Shubham Sharma $^{2} \cdot$ Vivek Aggarwal $^{2}$. Catalin I. Pruncu ${ }^{3,4}$ (1)}

Shubham Sharma

shubham543sharma@gmail.com; shubhamsharmacsirclri@gmail.com

Catalin I. Pruncu

Catalin.pruncu@strath.ac.uk; c.pruncu@imperial.ac.uk

Yadvinder Singh

yadvinder1986@gmail.com 
Jujhar Singh

jujharsingh2085@gmail.com

Vivek Aggarwal

agarwalz_v@yahoo.com

1 Research Scholar, Department of Mechanical Engineering, I.K. Gujral Punjab Technical University, VPO Ibban, Jalandhar-Kapurthala Highway, 144603 Jalandhar, India

2 Department of Mechanical Engineering, I.K. Gujral Punjab Technical University, VPO Ibban, Jalandhar-Kapurthala Highway, 144603 Jalandhar, India

3 Department of Mechanical Engineering, Imperial College London, Exhibition Road, SW7 2AZ London, UK

4 Design, Manufacturing \& Engineering Management, University of Strathclyde, G1 1XJ Glasgow, Scotland, UK 